\title{
Altered Lipid Metabolism in Human Platelets
}

\section{after Primary Aggregation}

\author{
Daniel Deykin \\ From the Department of Medicine, Beth Israel Hospital and Harvard Medical \\ School, Boston, Massachusetts 02215
}

\begin{abstract}
A в S T R A C T Thrombin and poly-l-lysine alter the incorporation of acetate, glycerol, and fatty acids into the lipids of washed human platelets. Both aggregating agents decrease the incorporation of acetate into all lipid classes other than free fatty acids. Similarly, glycerol incorporation into complex lipids is impaired by both thrombin and polylysine. Thrombin caused marked depression of the incorporation of palmitic acid into both lecithin and triglycerides. By contrast it enhanced the incorporation of oleic acid into lecithin, but not into triglycerides. The data suggest that the process of primary platelet aggregation is associated with a defect in the assembly of complex lipids.
\end{abstract}

\section{INTRODUCTION}

Platelets undergo unique reactions as they participate in the formation of a hemostatic plug. In a series of reactions initiated by the exposure of platelets first to collagen, then to adenosine diphosphate, and finally to thrombin, they swell, aggregate, and discharge many of their intracellular components into the surrounding plasma medium. The purpose of this report is to examine the effect of aggregation on the formation of platelet lipids from acetate, glycerol, and from fatty acids. We have used thrombin and poly-l-lysine as the aggregating agents to examine the specificity of the alterations in lipid metabolism.

Our data indicate that both thrombin and polylysine cause a marked impairment of fatty acid synthesis from acetate and complex lipid formation from both acetate and glycerol. Furthermore the uptake of saturated fatty acids from plasma and the subsequent incorporation of those fatty acids into complex lipids is markedly depressed by both aggregating agents but the incorporation of oleic acid into phospholipids is markedly enhanced.

Dr. Deykin is a recipient of Career Development Award HL-25261.

Receized for publication 22 August 1972 and in revised form 17 October 1972.

\section{METHODS}

Preparation of washed human platelets

Washed human platelets containing $0.6-1.5 \times 10^{9}$ platelets/ $\mathrm{ml}$ were prepared from normal subjects as previously described (1).

\section{Lipid preparations}

Sodium $\left[1{ }^{14} \mathrm{C}\right]$ acetate, $\left[2-{ }^{3} \mathrm{H}\right]$ glycerol, and $\left[1-{ }^{14} \mathrm{C}\right]$ palmitic, stearic, oleic, and linoleic acids were purchased from New England Nuclear Corp., Boston, Mass. The radiopurity of each of the fatty acid preparations, determined by gasliquid chromatography (GLC) was at least $97 \%$.

\section{Aggregating agents}

Human thrombin was purchased from Ortho Diagnostics, Raritan, N. J. Highly purified human thrombin was the gift of Dr. Kent Miller, University of Miami, Coral Gables, Fla. In preliminary experiments, we found no difference between the effects on lipid metabolism caused by equivalent amounts of either preparation. Therefore, the commercial preparation was routinely employed. Thrombin was assayed by a two-stage procedure as previously described (2).

Poly-l-lysine, average chain length $1250 \mathrm{U}$, was the gift of Dr. Stuart Schlossman, Beth Israel Hospital, Boston, Mass.

\section{Incubation techniques}

Acetate experiments. In general the incubations with acetate were similar to those previously described (1), except that the incubation medium contained $2.5 \mu \mathrm{mol}$ of $\mathrm{CaCl}_{2}$. No calcium-phosphate gels or precipitates occurred in our experiments in the presence or absence of platelets. Reactions were initiated by the addition of the platelet suspensions (prewarmed to $37^{\circ} \mathrm{C}$ for $5 \mathrm{~min}$ before addition) to the incubation flasks. The reactions were terminated by immersing the flasks in an ice bath for $2 \mathrm{~min}$ and then transferring the chilled contents of the flasks to iced centrifuge tubes. The platelets were then separated from the incubation medium by centrifugation at $2500 \mathrm{~g}$ for $15 \mathrm{~min}$ at $4^{\circ} \mathrm{C}$. Attempts to transfer aggregated platelets that had not been chilled led to variable recovery of platelets. Prechilling of the platelets before transferring led to complete recovery as determined by measuring the protein content of the platelet pellets after centrifugation. The platelets were then washed twice at $4^{\circ} \mathrm{C}$ with phosphate buffer, $\mathrm{pH}$ 
6.5 and finally resuspended in $2 \mathrm{ml}$ of buffer in preparation for lipid extraction.

In certain experiments $0.9 \mathrm{ml}$ of buffer was replaced by an equal volume of defibrinogenated plasma. The plasma was prepared by heating normal human plasma to $56^{\circ} \mathrm{C}$ for $30 \mathrm{~min}$, and then separating the precipitated fibrinogen and other denatured proteins by centrifugation. The plasma was then dialyzed extensively against modified Gaintner's buffer as previously described (1).

Fatty acid studies. Fatty acids were complexed to albumin in defibrinogenated plasma by dissolving the fatty acids ( $\mathrm{sp}$ act approximately $50 \mathrm{mCi} / \mathrm{mM}$ ) in acetone at a final concentration of $100 \mu \mathrm{Ci} / \mathrm{ml}$. $2.5 \mu \mathrm{l}$ of acetone $(0.25 \mu \mathrm{Ci}$, $5 \times 10^{-8} \mu$ eq) was added per milliliter of plasma by introducing the acetone under the surface of the plasma with constant swirling. The acetone was then driven off by incubation at $37^{\circ} \mathrm{C}$ for $1 \mathrm{~h}$ under a constant stream of nitrogen. The addition of this amount of fatty acid produced an insignificant change in the plasma free fatty acid concentration $(0.2-0.5 \mu \mathrm{eq} / \mathrm{ml})$. Incubations were conducted as in the acetate experiments, except that $0.9 \mathrm{ml}$ of labeled plasma replaced $0.9 \mathrm{ml}$ of buffer. The reactions were terminated as in the acetate experiments except that the platelets were washed twice in a solution of phosphate buffer: dialyzed (unlabeled) plasma, $\mathrm{pH} 6.5(1: 1 \mathrm{vol} / \mathrm{vol})$ to remove unreacted and dissociable fatty acids from the platelets.

Glycerol experiments. Incubations with glycerol were conducted as in the acetate experiments except that $\left[2{ }^{3} \mathrm{H}\right]$ glycerol replaced sodium $\left[1-{ }^{14} \mathrm{C}\right]$ acetate as the radioactive precursor. The concentration of glycerol was that employed by Lewis and Majerus (3), $10^{-4} \mathrm{~mol} / \mathrm{liter}$. In these studies no experiments with plasma were performed.

\section{Extraction of lipids}

Lipids were extracted from platelets and incubation media by a modified Folch procedure as previously described (1) except that the chloroform phase was washed five rather than three times.

\section{Thin-layer chromatography}

Lipid classes were resolved by bidirectional thin-layer chromatography (TLC) on Silica gel $\mathrm{H}$ as previously described (1), using solvent system I to resolve phospholipids and neutral lipids. In certain experiments the first direction of solvent system I, which does not resolve phosphatidyl serine and phosphatidyl inositol, was replaced by a system slightly modified from that described by Cohen, Derksen, and von den Bosch (4). Thin-layer plates were coated $(0.5 \mathrm{~mm})$ with a slurry prepared from $50 \mathrm{~g}$ Silica gel $\mathrm{H}, 0.5 \mathrm{~g}\left(\mathrm{NH}_{4}\right)_{2} \mathrm{HPO}_{4}$, and $110 \mathrm{ml}$ of water. Phospholipids were resolved with a solvent system of chloroform: methanol: acetic acid: water (150:90:24:9 vol/vol). In this system phosphatidyl serine and phosphatidyl inositol were separated, but phosphatidyl ethanolamine and ceramide were not well resolved.

\section{Gas-liquid chromatography}

The preparation of methyl esters of platelet and medium lipids and the subsequent separation of the esters by GLC were performed as previously described (1) except that the column was maintained at $180^{\circ} \mathrm{C}$.

\section{Assay of radioactivity}

The radioactivity of liquid extracts and of samples separated by TLC and GLC was assayed as previously described (1).

\section{RESULTS}

The effect of thrombin and poly-l-lysine on acetate incorporation into platelet lipids. In buffer incubations aggregation of platelets by both thrombin and polylysine impaired acetate incorporation into total platelet lipids (Fig. 1). For both agents the effect was a function of the concentration used to aggregate the platelets. At a concentration of $0.25 \mathrm{U} / \mathrm{ml}$ thrombin produced a $31 \%$ reduction of acetate incorporation into total lipids; at a thrombin concentration of $1 \mathrm{U} / \mathrm{ml}$ there was a $73 \%$ reduction of incorporation; at $5 \mathrm{U} / \mathrm{ml}$, thrombin completely blocked acetate incorporation. Polylysine caused a similar reduction of acetate incorporation into total lipids (Fig. 1). At a final concentration of $20 \mu \mathrm{g} / \mathrm{ml}$, there was a $65 \%$ reduction of lipid labeling. By contrast to thrombin, increasing concentrations of polylysine above $20 \mu \mathrm{g} / \mathrm{ml}$ produced little further effect on acetate incorporation. There was no release of newly labeled lipids into the buffer medium by either control platelets or by platelets aggregated by either thrombin or polylysine.

In plasma incubations the incorporation of acetate exhibited a different response to thrombin from that observed in buffer incubations (Fig. 2). At low doses of thrombin there was a stimulation of incorporation of acetate into total platelet lipids, and at a thrombin concentration of $1 \mathrm{U}$ there was only a $22 \%$ inhibition of acetate incorporation. At $5 \mathrm{U} / \mathrm{ml}$ however, there was a $59 \%$ reduction of acetate incorporation. As in our previous experiments (1) in the absence of thrombin approximately $40 \%$ of the radioactivity recovered in lipids was found in the plasma. Aggregation by thrombin did not alter the partition between platelets and plasma of lipids synthesized from acetate (Fig. 2).

Direct measurement of the stability of thrombin indicated that there was no decrease in thrombin activity in buffer over a $60 \mathrm{~min}$ interval. In plasma, however, thrombin activity fell rapidly during the initial minutes of incubation and was undetectable after $30 \mathrm{~min}$.

The time course of acetate incorporation into platelet lipids after aggregation by thrombin $(1 \mathrm{U} / \mathrm{ml})$ and by polylysine $(20 \mu \mathrm{g} / \mathrm{ml})$ was examined in buffer incubations (Table I). The aggregation of platelets after the addition of either agent was not immediate and continued for the initial 2-5 min of the incubation. At $5 \mathrm{~min}$, reflecting incorporation during the process of aggregation itself, there was minimal effect of thrombin on total lipid formation from acetate, but on continued incubation further incorporation into total lipids proceeded at a 

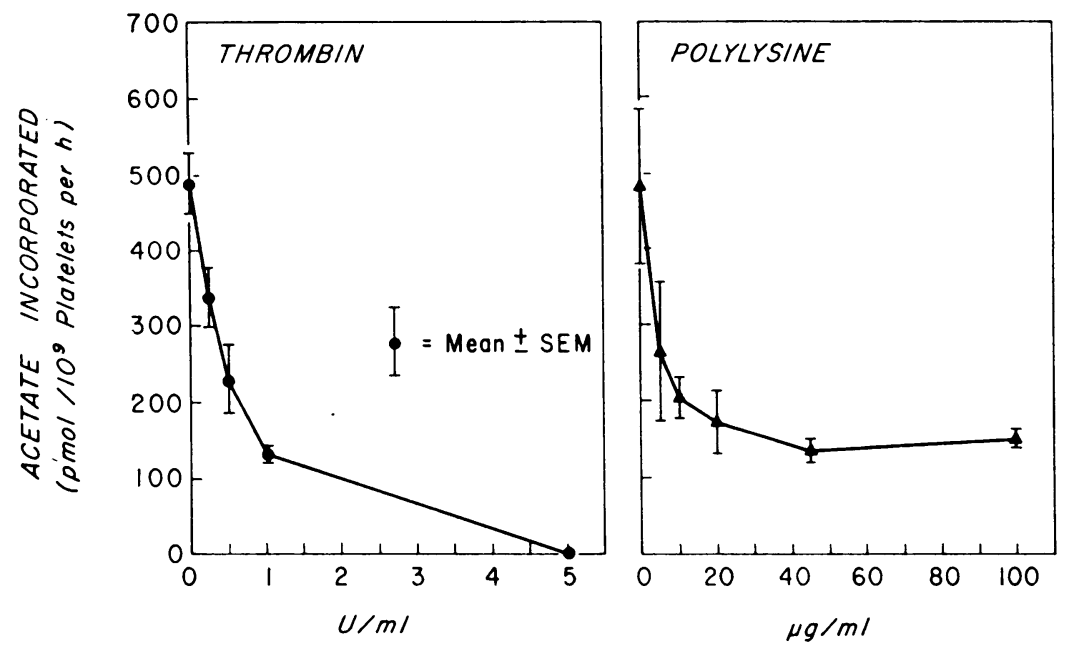

FIGURE 1 The effect of increasing concentrations of thrombin and poly-l-lysine on acetate incorporation into total platelet lipids. Each flask contained in a final volume of $2.0 \mathrm{ml}, 1.0$ $\mathrm{ml}$ of washed human platelets (approximately $10^{\circ} / \mathrm{ml}$ ) $1.0 \mathrm{ml}$ of modified Gaintner's phosphate buffer, $\mathrm{pH} 6.8$, and $5.0 \mu \mathrm{mol}$ of $\mathrm{Na}\left[1-{ }^{14} \mathrm{C}\right]$ acetate (sp act $10 \mu \mathrm{Ci} / \mu \mathrm{mol}$ ). Incubations were conducted for $60 \mathrm{~min}$ at $37^{\circ} \mathrm{C}$. Mean \pm SEM of 10 experiments for thrombin and 5 experiments for polylysine.

much slower rate than in control incubations. The differences were 'significant $(P<0.02)$ (Student's $t$ test) at $15 \mathrm{~min}$ (not shown) and highly significant $(P<$ 0.001 ) thereafter. There was diminished uptake of acetate into lipid classes except free fatty acids (Table I). Absolute incorporation of acetate into free fatty acids did not differ from control values at any time interval. Expressed as a percent of total incorporation, however, accumulation of radioactivity in free fatty acids was enhanced at all time intervals.

The effect of polylysine was similar to that of thrombin, in that after the formation of aggregates, incorporation of labeled acetate proceeded at a slower rate than in control flasks (Table I). The differences in total incorporation was significant $(P<0.02)$ at $30 \mathrm{~min}$, and was highly significant $(P<0.001)$ at $60 \mathrm{~min}$. As in the thrombin experiments, incorporation into all lipid classes other than free fatty acids was diminished (Table I), although to a lesser degree than in the thrombin-aggregated platelets. Again, when the radioactivity in free fatty acids was expressed as a percent of the total incorporated into all lipids, the contrast between the labeling of free fatty acids and the remaining lipid classes was apparent.

The effect of a lower thrombin concentration on the incorporation of acetate into platelet lecithin and free fatty acids is shown in Fig. 3. At a concentration of 0.1 $\mathrm{U} / \mathrm{ml}$, total incorporation during the first $30 \mathrm{~min}$ of incubation did not differ from the control values, although there was a decline in incorporation after $30 \mathrm{~min}$. Incorporation into fatty acids exceeded that of the con- trols. By contrast, incorporation into lecithin was decreased at all time intervals.

To examine the effect of thrombin and polylysine on the synthesis of individual fatty acids from acetate, methyl esters of fatty acids were prepared from total platelet lipid extracts, and individual fatty acids were resolved by GLC. In control and in both thrombin- and

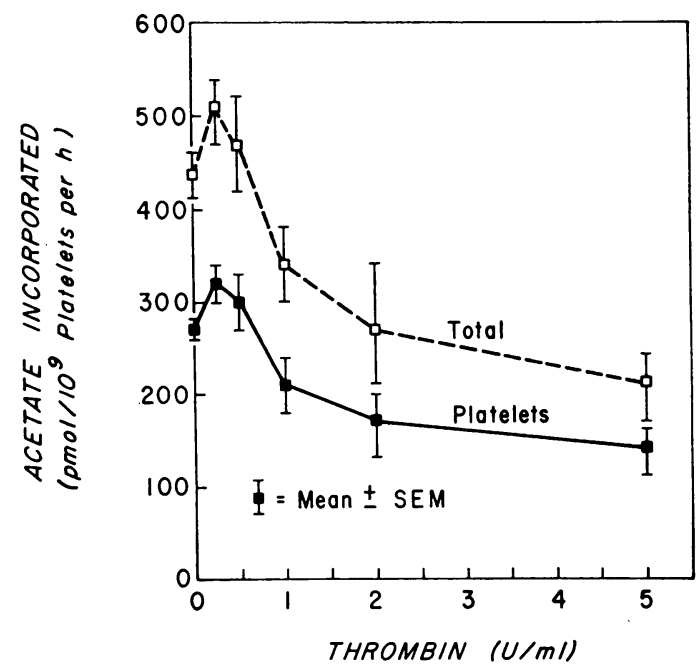

FIGURE 2 Effect of increasing thrombin concentration on acetate incorporation into total platelet lipids in plasma. Conditions as in Fig. 1 except that $0.9 \mathrm{ml}$ of defibrinogenated dialyzed plasma replaces an equivalent volume of buffer. Mean ISEM 5 experiments. Total: Radioactivity in platelets and media combined. Platelets: radioactivity in platelets alone. 
TABLE I

The Effect of Thrombin and Polylysine on Acetate Incorporation into Platelet Lipids

\begin{tabular}{|c|c|c|c|c|c|c|c|c|c|}
\hline \multicolumn{4}{|c|}{ Control* } & \multicolumn{3}{|c|}{ Thrombin $\ddagger$} & \multicolumn{3}{|c|}{ Polylysine\$ } \\
\hline \multicolumn{4}{|c|}{ Minutes of incubation } & \multicolumn{3}{|c|}{ Minutes of incubation } & \multicolumn{3}{|c|}{ Minutes of incubation } \\
\hline$\|$ & 5 & 30 & 60 & 5 & 30 & 60 & 5 & 30 & 60 \\
\hline PC & $\begin{array}{r}1.6 \pm 0.29 \\
(5.2)^{* *}\end{array}$ & $\begin{array}{c}24.6 \pm 4.4 \\
(12.2)\end{array}$ & $\begin{array}{c}56.1 \pm 6.1 \\
(13.9)\end{array}$ & $\begin{array}{c}1.7 \pm 0.3 \\
(6.8)\end{array}$ & $\begin{array}{c}7.8 \pm 1.8 \\
(9.7)\end{array}$ & $\begin{array}{c}12.0 \pm 3.5 \\
(10.6)\end{array}$ & $\begin{array}{c}3.5 \pm 0.2 \\
(9.5)\end{array}$ & $\begin{array}{c}14.6 \pm 2.4 \\
(10.6)\end{array}$ & $\begin{array}{c}25.0 \pm 6.1 \\
(14.4)\end{array}$ \\
\hline PS and PI & $\begin{array}{c}1.0 \pm 0.0 \\
(3.2)\end{array}$ & $\begin{array}{c}7.9 \pm 2.3 \\
(3.9)\end{array}$ & $\begin{array}{c}9.7 \pm 2.2 \\
(2.4)\end{array}$ & $\begin{array}{c}1.0 \pm 0.0 \\
(4.0)\end{array}$ & $\begin{array}{c}3.3 \pm 1.1 \\
(4.1)\end{array}$ & $\begin{array}{c}4.0 \pm 2.1 \\
(3.5)\end{array}$ & $\begin{array}{c}2.1 \pm 0.2 \\
(5.7)\end{array}$ & $\begin{array}{l}8.5 \pm 2.7 \\
(6.2)\end{array}$ & $\begin{array}{c}9.8 \pm 3.9 \\
(5.6)\end{array}$ \\
\hline $\mathrm{PE}$ & $\begin{array}{c}1.7 \pm 0.2 \\
(5.5)\end{array}$ & $\begin{array}{c}14.8 \pm 2.2 \\
\quad(7.3)\end{array}$ & $\begin{array}{c}28.7 \pm 2.7 \\
(7.1)\end{array}$ & $\begin{array}{c}1.3 \pm 0.3 \\
(5.2)\end{array}$ & $\begin{array}{c}3.8 \pm 0.8 \\
(4.7)\end{array}$ & $\begin{array}{c}7.0 \pm 1.6 \\
(6.2)\end{array}$ & $\begin{array}{c}1.7 \pm 0.3 \\
(4.6)\end{array}$ & $\begin{array}{c}13.5 \pm 9.5 \\
(9.8)\end{array}$ & $\begin{array}{c}23.0 \pm 15.6 \\
(13.2)\end{array}$ \\
\hline CER & $\begin{array}{c}15.3 \pm 2.6 \\
(49.7)\end{array}$ & $\begin{array}{c}102.4 \pm 8.1 \\
\quad(50.6)\end{array}$ & $\begin{array}{c}223.7 \pm 17.4 \\
(55.4)\end{array}$ & $\begin{array}{c}12.0 \pm 2.0 \\
(48.0)\end{array}$ & $\begin{array}{c}39.4 \pm 2.1 \\
(49.1)\end{array}$ & $\begin{array}{c}54.5 \pm 4.5 \\
(48.2)\end{array}$ & $\begin{array}{c}13.6 \pm 0.3 \\
(37.0)\end{array}$ & $\begin{array}{c}58.0 \pm 8.7 \\
(42.0)\end{array}$ & $\begin{array}{c}69.3 \pm 14.0 \\
(33.9)\end{array}$ \\
\hline DG & $\begin{array}{c}3.0 \pm 0.4 \\
(9.7)\end{array}$ & $\begin{array}{c}18.6 \pm 2.1 \\
(9.2)\end{array}$ & $\begin{array}{c}30.0 \pm 2.4 \\
(7.4)\end{array}$ & $\begin{array}{c}2.0 \pm 0.6 \\
(8.0)\end{array}$ & $\begin{array}{c}5.0 \pm 0.4 \\
(6.2)\end{array}$ & $\begin{array}{c}7.8 \pm 1.5 \\
(6.9)\end{array}$ & $\begin{array}{c}1.8 \pm 0.1 \\
(4.9)\end{array}$ & $\begin{array}{c}6.0 \pm 0.8 \\
(4.3)\end{array}$ & $\begin{array}{c}9.2 \pm 2.4 \\
(5.3)\end{array}$ \\
\hline FFA & $\begin{array}{c}7.2 \pm 1.7 \\
(23.4)\end{array}$ & $\begin{array}{c}15.8 \pm 2.6 \\
(7.8)\end{array}$ & $\begin{array}{c}23.7 \pm 3.1 \\
(5.9)\end{array}$ & $\begin{array}{l}8.0 \pm 1.0 \\
(32.0)\end{array}$ & $\begin{array}{c}19.8 \pm 4.1 \\
(24.7)\end{array}$ & $\begin{array}{c}19.3 \pm 4.3 \\
(17.1)\end{array}$ & $\begin{array}{c}7.3 \pm 1.9 \\
(19.8)\end{array}$ & $\begin{array}{c}29.5 \pm 5.4 \\
\quad(21.4)\end{array}$ & $\begin{array}{c}26.5 \pm 5.1 \\
(15.3)\end{array}$ \\
\hline TG & $\begin{array}{c}2.8 \pm 0.3 \\
(9.1)\end{array}$ & $\begin{array}{c}8.5 \pm 1.3 \\
(4.2)\end{array}$ & $\begin{array}{c}18.0 \pm 1.5 \\
\quad(4.6)\end{array}$ & $\begin{array}{c}1.0 \pm 0.0 \\
(4.0)\end{array}$ & $\begin{array}{c}1.4 \pm 0.2 \\
(1.7)\end{array}$ & $\begin{array}{c}3.0 \pm 0.4 \\
(2.7)\end{array}$ & $\begin{array}{c}3.0 \pm 0.4 \\
(8.2)\end{array}$ & $\begin{array}{c}3.2 \pm 0.2 \\
(2.3)\end{array}$ & $\begin{array}{c}5.6 \pm 1.0 \\
(3.2)\end{array}$ \\
\hline TOTAL & $\begin{array}{c}32.6 \pm 3.3 \\
\quad(100)\end{array}$ & $\begin{array}{c}192.6 \pm 15.6 \\
(100)\end{array}$ & $\begin{array}{c}389.9 \pm 25.6 \\
(100)\end{array}$ & $\begin{array}{l}27.0 \pm 1.0 \\
(100)\end{array}$ & $\begin{array}{l}80.5 \pm 10.1 \\
\quad(100)\end{array}$ & $\begin{array}{c}107.6 \pm 17.0 \\
(100)\end{array}$ & $\begin{array}{c}33.0 \pm 3.1 \\
(100)\end{array}$ & $\begin{array}{c}133.3 \pm 26.9 \\
(100)\end{array}$ & $\begin{array}{c}168.4 \pm 45.4 \\
\quad(100)\end{array}$ \\
\hline
\end{tabular}

* Eight experiments, each determination in duplicate.

$\ddagger$ Human thrombin, $1 \mathrm{U} / \mathrm{ml}$. Five experiments, each determination in duplicate.

\&oly-l-lysine, $20 \mu \mathrm{g} / \mathrm{ml}$. Three experiments, each determination in duplicate.

II Abbreviations, PC, phosphatidyl choline; PS, phosphatidyl serine; PI, phosphatidyl inositol; PE, phosphatidyl ethanolamine; ClER,

ceramide; DG, diglyceride; FFA, free fatty acid; TG, triglyceride.

I Picomoles acetate incorporated $/ 10^{\circ}$ platelets. Mean \pm SEM. Incubation conditions as in Fig. 1.

** Percent of total incorporation at each time point.

polylysine-aggregated platelets, radioactivity accumulated primarily in saturated fatty acids from $\mathrm{C} 14: 0$ to those longer than $\mathrm{C} 24: 0$. For clarity of presentation the fatty acids were grouped into those labeled by de novo synthesis ( $<\mathrm{C16:0}$ ) and those labeled by both de novo synthesis and chain elongation (Table II). Both thrombin and polylysine initially stimulated incorporation of acetate into fatty acids formed by de novo synthesis. After $10 \mathrm{~min}$, however, labeling by de novo synthesis slowed appreciably (polylysine) or ceased entirely
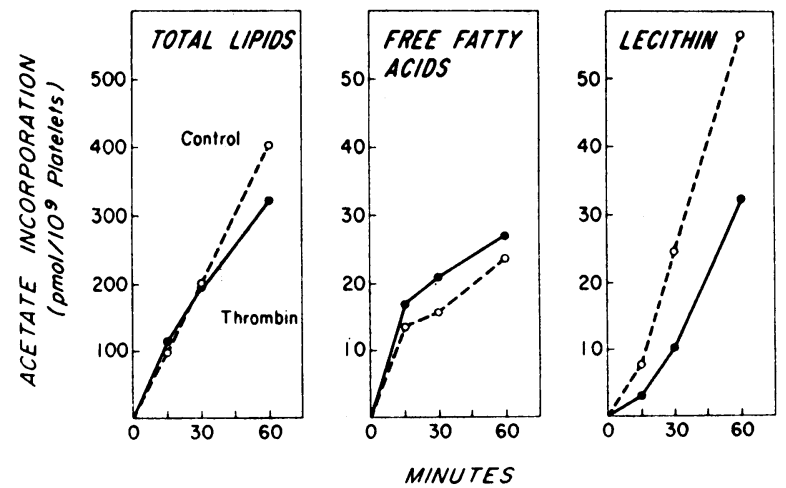

FIGURE 3 Time course of incorporation of acetate into platelet lipids. Conditions as in Fig. 1 and Table I except that the final thrombin concentration is $0.1 \mathrm{U} / \mathrm{ml}$. Mean of duplicate determinations.
TABLE II

Fatty Acid Distribution of Fatty Acids Formed from Acetate

\begin{tabular}{clcrr}
\hline $\begin{array}{c}\text { Minutes of } \\
\text { incubation }\end{array}$ & & & & \\
\hline \multirow{2}{*}{10} & Control & $10^{*}$ & 61 & 71 \\
& Thrombin $\ddagger$ & 28 & 53 & 81 \\
& Polylysine $\$$ & 24 & 60 & 84 \\
& Control & 23 & 115 & 138 \\
20 & Thrombin & 30 & 54 & 84 \\
& Polylysine & 37 & 122 & 159 \\
& Control & 41 & 193 & 234 \\
30 & Thrombin & 28 & 52 & 80 \\
& Polylysine & 38 & 144 & 182 \\
& Control & 109 & 371 & 480 \\
60 & Thrombin & 34 & 72 & 116 \\
& Polylysine & 73 & 180 & 253 \\
\hline
\end{tabular}

Methyl esters of platelet fatty acids were prepared from total lipid extracts. Carrier methyl ester standards were added and individual fatty acids were resolved by GLC. A stream splitter diverted $70 \%$ of the column effluent to a port at which individual fatty acids were collected for radioactivity measurement.

* Picomoles incorporated $/ 10^{9}$ platelets.

$\ddagger 1.0 \mathrm{U} / \mathrm{ml}$.

$\S 20 \mu \mathrm{g} / \mathrm{ml}$. 
(thrombin). There was no stimulation of fatty acid synthesis by chain elongation at any point. In thrombin incubations, no further labeling occurred in fatty acids longer than palmitic after $10 \mathrm{~min}$. In polylysine incubations the rate of labeling of these fatty acids proceeded as in control flasks for $20 \mathrm{~min}$ but progressively diminished thereafter.

The effects of thrombin and poly-l-lysine on the synthesis of platelct lipids from glycerol. Both aggregating agents produced a decrease in glycerol incorporation into platelet lipids (Fig. 4) most apparent at the earlier intervals. At $5 \mathrm{~min}$ there was an $84 \%$ reduction in glycerol incorporation into total lipids in thrombin-aggregated platelets compared with control platelets and a $71 \%$ decrease of glycerol incorporation into total lipids in polylysine-aggregated platelets. After $30 \mathrm{~min}$ of incubation, the rates of incorporation of glycerol into total lipids were more similar to those of control platelets.

Glycerol was incorporated into both phospholipids and neutral lipids. In preliminary experiments we utilized a modification of the solvent system described by Cohen and his associates (4) to resolve phosphatidyl serine from phosphatidyl inositol. At all time points over $90 \%$ of the radioactivity of the two phospholipids together was present as phosphatidyl inositol. Since the combined total did not exceed $20 \%$ of the total glycerol incorporated by control platelets, and since the effect of aggregation was to reduce further the counts in both fractions, in subsequent experiments we employed our usual solvent system which does not resolve phosphatidyl serine from phosphatidyl inositol, but does resolve lecithin and phosphatidyl ethanolamine clearly from other phospholipids.

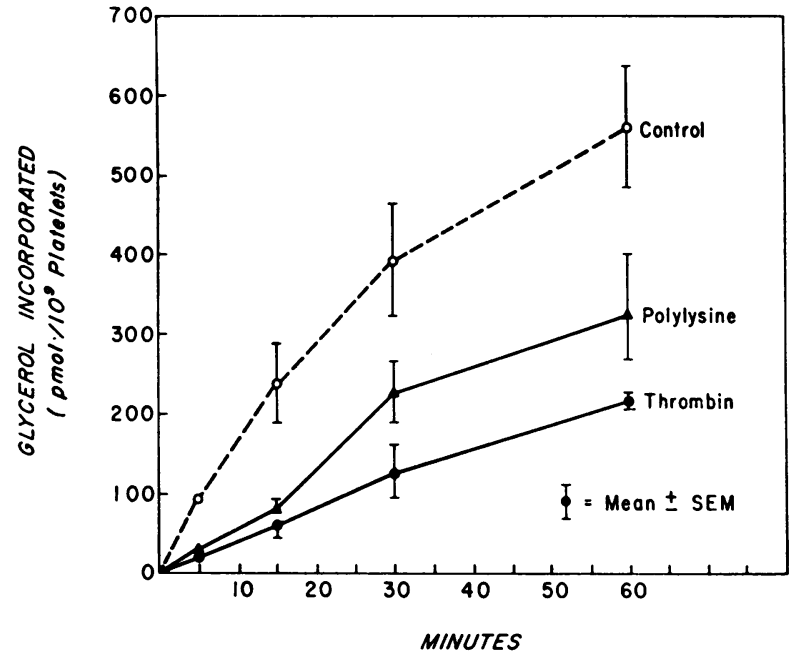

FIgURE 4 Time course of incorporation of glycerol into platelet lipids. Conditions as in Fig. 1 except that acetate is replaced by $0.2 \mu \mathrm{mol}$ of $\left[2-{ }^{3} \mathrm{H}\right]$ glycerol (sp act $50 \mu \mathrm{Ci}$ / $\mu \mathrm{mol})$. Final thrombin concentration: $1 \mathrm{U} / \mathrm{ml}$; final polylysine concentration: $20 \mu \mathrm{g} / \mathrm{ml}$. Mean $\pm S E M$ of three experiments.

At early time points half of the total glycerol incorporated by control platelets was present in glycerides (Table III). At longer time intervals, incorporation into phospholipids predominater. Aggregation by both thrombin and polylysine caused an absolute decrease in glycerol uptake into all lipid classes at all time intervals (although we did not exclude an increment into phosphatidyl serine). There were interesting differences in the rates of incorporation into the various lipids, most apparent when the incorporation was expressed as a per-

TABLE III

The Effect of Thrombin and Polylysine on Glycerol Incorporation into Platelet Lipids

\begin{tabular}{|c|c|c|c|c|c|c|c|c|c|}
\hline \multicolumn{4}{|c|}{ Control* } & \multicolumn{3}{|c|}{ Thrombin $\ddagger$} & \multicolumn{3}{|c|}{ Polylysine§ } \\
\hline \multicolumn{4}{|c|}{ Minutes of incubation } & \multicolumn{3}{|c|}{ Minutes of incubation } & \multicolumn{3}{|c|}{ Minutes of incubation } \\
\hline it & 5 & 30 & 60 & 5 & 30 & 60 & 5 & 30 & 60 \\
\hline $\mathrm{PC}$ & $\begin{array}{r}18.5 \pm 3.6 \pi \\
(19.5)^{* *}\end{array}$ & $\begin{array}{c}132.9 \pm 28.4 \\
(33.9)\end{array}$ & $\begin{array}{c}207.1 \pm 23.2 \\
\quad(37.0)\end{array}$ & $\begin{array}{c}2.4 \pm 0.4 \\
(16.1)\end{array}$ & $\begin{array}{c}31.2 \pm 9.2 \\
(24.0)\end{array}$ & $\begin{array}{l}44.0 \pm 8.0 \\
\quad(21.2)\end{array}$ & $\begin{array}{c}5.8 \pm 0.8 \\
(20.6)\end{array}$ & $\begin{array}{c}61.7 \pm 8.9 \\
(27.0)\end{array}$ & $\begin{array}{c}105.3 \pm 29.4 \\
(32.4)\end{array}$ \\
\hline PS and PI & $\begin{array}{c}19.8 \pm 2.7 \\
\quad(20.9)\end{array}$ & $\begin{array}{c}68.1 \pm 7.1 \\
\quad(17.3)\end{array}$ & $\begin{array}{l}116.6 \pm 22.5 \\
\quad(20.7)\end{array}$ & $\begin{array}{c}5.7 \pm 1.0 \\
(38.2)\end{array}$ & $\begin{array}{c}50.2 \pm 15.7 \\
\quad(40.0)\end{array}$ & $\begin{array}{c}61.7 \pm 1.3 \\
(30.5)\end{array}$ & $\begin{array}{c}7.5 \pm 1.3 \\
(26.9)\end{array}$ & $\begin{array}{c}61.2 \pm 14.1 \\
\quad(26.8)\end{array}$ & $\begin{array}{l}64.7 \pm 16.3 \\
\quad(19.6)\end{array}$ \\
\hline PE & $\begin{array}{c}8.2 \pm 1.2 \\
(8.6)\end{array}$ & $\begin{array}{c}39.0 \pm 4.1 \\
(9.9)\end{array}$ & $\begin{array}{c}78.9 \pm 14.0 \\
(14.1)\end{array}$ & $\begin{array}{c}2.6 \pm 0.3 \\
(17.4)\end{array}$ & $\begin{array}{c}18.4 \pm 3.4 \\
\quad(14.3)\end{array}$ & $\begin{array}{l}45.1 \pm 22.4 \\
\quad(21.6)\end{array}$ & $\begin{array}{c}4.4 \pm 0.9 \\
(15.8)\end{array}$ & $\begin{array}{c}38.4 \pm 6.3 \\
(16.6)\end{array}$ & $\begin{array}{c}42.6 \pm 5.7 \\
(13.0)\end{array}$ \\
\hline DG & $\begin{array}{c}12.1 \pm 1.8 \\
\quad(12.7)\end{array}$ & $\begin{array}{l}40.3 \pm 7.1 \\
\quad(10.3)\end{array}$ & $\begin{array}{c}62.7 \pm 10.4 \\
\quad(11.2)\end{array}$ & $\begin{array}{c}1.6 \pm 0.2 \\
(10.7)\end{array}$ & $\begin{array}{c}16.7 \pm 3.2 \\
(12.8)\end{array}$ & $\begin{array}{c}30.6 \pm 0.9 \\
(14.6)\end{array}$ & $\begin{array}{c}4.7 \pm 0.8 \\
(16.8)\end{array}$ & $\begin{array}{c}45.4 \pm 9.7 \\
\quad(19.8)\end{array}$ & $\begin{array}{l}74.6 \pm 14.3 \\
\quad(23.0)\end{array}$ \\
\hline TG & $\begin{array}{c}33.8 \pm 7.7 \\
\quad(35.2)\end{array}$ & $\begin{array}{c}104.6 \pm 27.8 \\
(26.6)\end{array}$ & $\begin{array}{c}81.6 \pm 9.8 \\
(14.5)\end{array}$ & $\begin{array}{c}2.4 \pm 0.5 \\
(16.1)\end{array}$ & $\begin{array}{c}10.9 \pm 2.8 \\
(8.4)\end{array}$ & $\begin{array}{c}13.7 \pm 1.9 \\
(6.6)\end{array}$ & $\begin{array}{c}4.4 \pm 0.7 \\
(15.8)\end{array}$ & $\begin{array}{c}15.8 \pm 2.6 \\
(6.9)\end{array}$ & $\begin{array}{c}29.1 \pm 8.7 \\
(8.9)\end{array}$ \\
\hline
\end{tabular}

* Three experiments, each in duplicate.

$\mp$ Thrombin, $1 \mathrm{U} / \mathrm{ml}$.

$\$$ Poly-l-lysine, $20 \mu \mathrm{g} / \mathrm{ml}$.

Ii Abbreviations as in Table I.

T Picomoles glycerol incorporated $/ 10^{9}$ platelets. Mean $\pm \mathrm{SEM}$. Incubation conditions as in Fig. 5

** Percent of total at each time interval. 

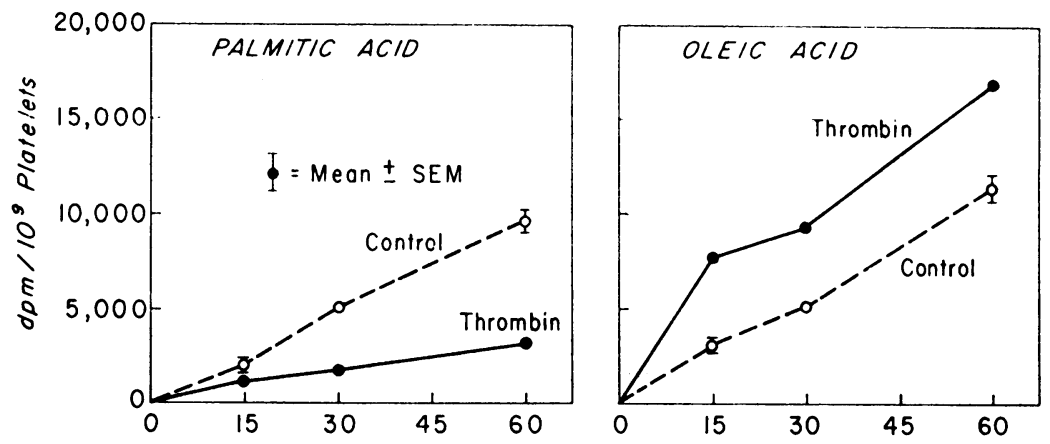

MINUTES

FIGURE 5 Effect of thrombin on the incorporation of $\left[1-{ }^{14} \mathrm{C}\right]$ palmitic acid and $\left[1-{ }^{14} \mathrm{C}\right]$ oleic acid into platelet lecithin. Final thrombin concentration $5 \mathrm{U} / \mathrm{ml}$. Mean $\pm \mathrm{SEM}$ of three experiments.

cent of the total glycerol incorporated at each time point. In control platelets, glycerol incorporated into lecithin represented a progressively increasing proportion of the total; conversely, triglyceride radioactivity, greatest at $5 \mathrm{~min}$ thereafter constituted a progressively decreasing fraction of the total.

Both thrombin and polylysine caused alterations in these patterns of distribution of radioactivity. In aggregated platelets, the relative increment in lecithin platelets either did not occur (thrombin) or was attenuated (polylysine). At $60 \mathrm{~min}$, when $37 \%$ of the total radioactivity in control platelets was present in lecithin, in thrombin-treated platelets lecithin comprised only $21 \%$ of the total. In control platelets triglycerides contained $35 \%$ of the total glycerol taken up by the platelets at 5 min, but only $16 \%$ of the total in both thrombin-aggregated platelets and in polylysine-aggregated platelets. In longer incubations the fraction of the total radioactivity in triglycerides declined still further.

The effect of thrombin and poly-l-lysine on the incorporation of preformed fatty acids into platelet lipids. Both thrombin and polylysine altered the incorporation of labeled fatty acids into the complex lipids of platelets. Thrombin decreased the incorporation of palmitic acid into lecithin at all time intervals (Fig. 5). By contrast, it stimulated the incorporation of oleic acid into lecithin (Fig. 6). The stimulation was most evident during the first $15 \mathrm{~min}$ of incubation. Thereafter, the rate of incorporation paralleled that of nonaggregated platelets. In other experiments (not shown) we found that the incorporation of stearic acid into lecithin was depressed by thrombin, while that of linoleic acid did not differ from control values. In contrast to its effects on lecithin formation, thrombin depressed the incorporation of both palmitic and oleic acids into platelet triglycerides (Fig. 6). Similarly, the incorporation of stearic and linoleic acids into triglycerides was also depressed by thrombin.

The pattern of incorporation of fatty acids into phosphatidyl ethanolamine was similar to that observed for lecithin (Fig. 7). Thrombin depressed incorporation of palmitic and stearic acids, enhanced the incorporation of oleic acid and did not alter the overall rate of incorporation of linoleic acid. There was minimal alteration in the

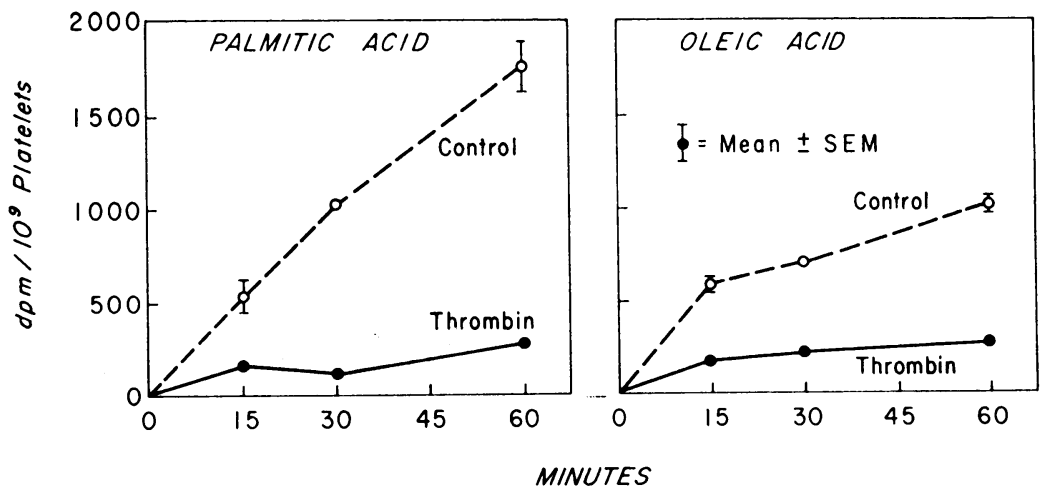

FIGURE 6 Effect of thrombin on incorporation of $\left[1{ }^{14} \mathrm{C}\right]$ palmitic acid and $\left[1-{ }^{14} \mathrm{C}\right]$ oleic acid into platelet triglycerides. Mean \pm SEM of three experiments. 
incorporation of the four fatty acids into the combined phosphatidyl serine and inositol fractions.

The effects of polylysine were similar in that the incorporation of saturated fatty acids into lecithin and phosphatidyl ethanolamine was depressed (Fig. 7). However, in polylysine-aggregated platelets the overall rates of incorporation of oleic and linoleic acids into lecithin and phosphatidyl ethanolamine were both similar to control values; no stimulation of oleic acid incorporation was observed. There was only slight depression of labeling of phosphatidyl serine and inositol by the saturated fatty acids. As with thrombin, polylysine depressed the formation of triglycerides from all four fatty acids.

In both control and in aggregated platelets there was heavy labeling of the platelet free fatty acid fraction by each of the fatty acids studied. Since the platelets were washed extensively with unlabeled plasma before extraction, the radioactivity present in the free fatty acid fraction represented fatty acids bound by the platelet, presumably at the plasma membrane (5-7). There was no consistent change in the free fatty acid radioactivity during incubation, in either control or aggregated platelets. Representative experiments are described in Table IV. Neither the stimulation of incorporation of oleic acid into lecithin by thrombin nor the depression of stearic acid incorporation into lecithin by polylysine nor the impaired incorporation of all four fatty acids into triglyceride reflecterl changes in free fatty acid radioactivity.

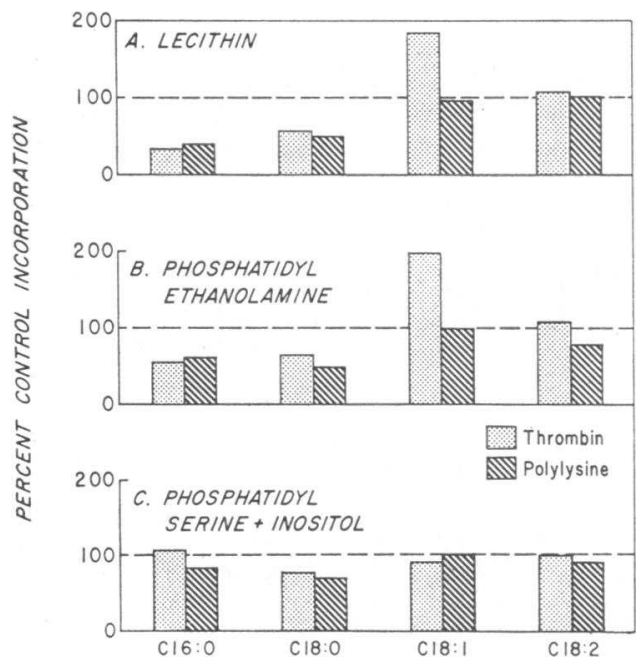

FIgURE 7 Effect of thrombin and polylysine on the incorporation of fatty acids into platelet phospholipids. Incubations conducted at $37^{\circ} \mathrm{C}$ for $30 \mathrm{~min}$. Data expressed as percent of control incorporation for each fatty acid into each phospholipid class. Mean of three experiments.
TABLE IV

Radioactivity in Platelet Lecithin and Free Fatty Acids

\begin{tabular}{|c|c|c|c|c|}
\hline \multirow{2}{*}{$\begin{array}{l}\text { Minutes of } \\
\text { incubation }\end{array}$} & \multicolumn{2}{|c|}{ Control* } & \multicolumn{2}{|c|}{ Polylysine } \\
\hline & Lecithin & $\mathrm{FFA}$ & Lecithin & FFA \\
\hline \multicolumn{5}{|l|}{ Stearic acid } \\
\hline 5 & 140 & $295 t$ & 121 & 3691 \\
\hline 15 & 457 & 2188 & 198 & 2495 \\
\hline 30 & 1054 & 1955 & 355 & 2007 \\
\hline 60 & 1979 & 2447 & 857 & 2660 \\
\hline \multicolumn{5}{|l|}{ Oleic acid } \\
\hline 5 & 388 & 2452 & 1183 & 2644 \\
\hline 15 & 814 & 4261 & 2237 & 2471 \\
\hline 30 & 1152 & 4213 & 2487 & 4513 \\
\hline 60 & 3157 & 3477 & 3927 & 3976 \\
\hline
\end{tabular}

${ }^{*} \mathrm{dpm} / 10^{9}$ platelets. Mean of duplicate determinations. $\ddagger 20 \mu \mathrm{g} / \mathrm{ml}$, final concentration.

$\$ 5 \mathrm{U} / \mathrm{ml}$, final concentration.

\section{DISCUSSION}

In our previous study of acetate incorporation into platelet lipids we demonstrated (1) as have several others ( 8-10), that the platelet is capable of both de novo synthesis of fatty acids as well as chain elongation. In buffer incubations we found that after 60 min of incubation, $75 \%$ of the total lipid radioactivity was found in three major classes: ceramide, lecithin, and free fatty acids. In plasna incubations, exchange of labeled intracellular iree fatty acids with the large unlabeled pool of albuminbound plasma free fatty acids trapped labeled free fatty acids formed within the platelet in the plasma incubation medium. As a result, in plasma incubations $40 \%$ of the total lipid radioactivity was found in the plasma, virtually all in free fatty acids, but in buffer incubations in the absence of a receptor protein for free fatty acids, no newly labeled lipids were released into the medium.

The data presented in Fig. 1 demonstrate that both thrombin and polylysine impair the overall incorporation of acetate into platelet lipids. At a concentration of 1 $\mathrm{U} / \mathrm{ml}$ of thrombin and $20 \mu \mathrm{g} / \mathrm{ml}$ of polylysine there was a comparable fall of acetate incorporation from 480 pmol $/ 10^{\circ}$ platelets per $\mathrm{h}$ to $133 \mathrm{pmol} / 10^{\circ}$ platelets per $\mathrm{h}$, a decrement of $65 \%$.

In plasma incubations (Fig. 2) higher concentrations of thrombin were required to produce a decrease of acetate incorporation, presumably due to rapid inactivation of thrombin by plasma antithrombin, which survives, at least partially, heating to $56^{\circ} \mathrm{C}$ for $30 \mathrm{~min} .^{1}$ Thrombininduced aggregation of platelets in plasma did not alter the distribution of newly labeled lipids between platelets and plasma, indicating that the process of aggregation

\footnotetext{
${ }^{1}$ Rosenberg, R. D. Unpublished observations.
} 
does not prevent exchange of free fatty acids between platelets and plasma.

The time course of incorporation of acetate into total lipids was linear in control platelets (Table I). At early time points both polylysine- and thrombin-aggregated platelets took up as much acetate into platelet lipids as nonaggregated platelets, but thereafter the rate of incorporation progressively declined. As indicated in $\mathrm{Ta}$ ble I, however, the effect of aggregation was not uniform in that the incorporation of acetate into free fatty acids in aggregated platelets did not differ from the control values whereas the incorporation into all other lipid classes was impaired. The data in Table II extend these observations in that they indicate that at $10 \mathrm{~min}$ when neither agent had yet caused a decrease in total incorporation, there was a stimulation of fatty acid formation by de novo synthesis.

The data in Fig. 3 indicate that a defect in complex lipid formation can be distinguished from the overall impairment of acetate incorporation. At a dose of 0.1 $\mathrm{U} / \mathrm{ml}$, thrombin did not affect total acetate incorporation for at least $30 \mathrm{~min}$. Concomitantly, the free fatty acid fraction in the thrombin-aggregated platelets was labeled to at least the same degree, as in the control platelets. Nevertheless, there was a decrease in acetate incorporation into lecithin at all time points.

The data from the glycerol incorporation studies (Fig. 4, Table III) further support the hypothesis that complex lipid formation is impaired in aggregated platelets. Both thrombin and polylysine caused an absolute decrease in the incorporation of radioactive glycerol into all classes of platelet lipids. Our data support and extend the findings of Lewis and Majerus (3) who have previously studied in detail the incorporation of glycerol into human platelet lipid phosphatides. By isolating the individual phospholipids and then subjecting them to alkaline hydrolysis and analysis of the water soluble products, these authors demonstrated the de novo synthesis of phosphoglycerides from glycerol. In their experiments with control platelets they found only $6 \%$ of the total glycerol incorporated into neutral lipids after $1 \mathrm{~h}$ in contrast to the $28 \%$ of the total in our experiments. The relative amounts of incorporation into lecithin, phosphatidyl ethanolamine, and phosphatidyl serine and inositol, however, in our experiments are quite similar to those of Lewis and Majerus. The differences may be technical in that the conditions of incubation in our experiments, and the technique of preparing washed platelets were not identical.

These authors have previously reported that thrombin causes an impairment of glycerol incorporation into phospholipids. They did not investigate the effects of thrombin on neutral lipid synthesis. We did not observe the absolute increase in glycerol incorporation into phospha- tidyl serine reported by Lewis and Majerus, but we did not study time points earlier than $5 \mathrm{~min}$. We found, as did they, that thrombin caused a preferential decrement in lecithin formation, but they did not report the effect of thrombin on triglyceride synthesis.

As with the acetate experiments we have not excluded the possibility that a portion of the decreased incorporation reflected dilution of the intracellular pool of glycerol, thereby producing an apparent decrease in the rate of formation of complex lipids. Indeed, several authors have demonstrated that thrombin stimulates glycolysis which might well dilute the specific activity of the intracellular pools of glycerol (11-14). However, the reported stimulation of glycolysis by thrombin was apparent only after a significant delay whereas in our experiments the effects of thrombin on complex lipid formation was most apparent at early time points and became less evident after $30 \mathrm{~min}$. In addition the effects of both polylysine and thrombin were not uniform. If the decrement in incorporation reflected only dilution of labeled precursors, then we would have expected uniform dilution of label in all lipid classes. In addition the exogenous pools of added substrate were so large as to render unlikely the enormous dilution required from endogenous pools.

The studies of fatty acid incorporation provide direct evidence for impaired complex lipid synthesis in aggregated platelets. As indicated in Fig. 5 and 6 in thrombinaggregated platelets there was a decrease in the transfer of albumin-bound palmitic acid into lecithin and into triglyceride. We observed a similar decrease in stearic acid incorporation into both triglyceride and lecithin. Furthermore, there was also a decrease in the incorporation of these two saturated fatty acids into phosphatidyl ethanolamine (Fig. 7).

In contrast to the effect of aggregating agents on saturated fatty acid incorporation, thrombin caused enhancement of oleic acid incorporation into both lecithin and phosphatidyl ethanolamine, but triglyceride synthesis was impaired to the same extent as with saturated fatty acids. There was an intermediate effect of thrombin on the incorporation of linoleic acid: uptake into triglycerides was depressed, but total incorporation into lecithin and phosphatidyl ethanolamine was apparently not altered. Polylysine caused alterations in the pattern of incorporation that were similar to those of thrombin, differing only in that the incorporation of oleic acid resembled that of linoleic; neither stimulation nor depression of incorporation into phospholipids was seen, but triglyceride synthesis was strikingly depressed.

Our data, of which representative experiments are shown in Table IV are consistent with those of Spector, Hoak, Warner, and Fry (5). We have found that the bulk of fatty acids taken up by the platelet remain as 
free fatty acids; that there is not a major change in free fatty acid radioactivity during the incubation but that the incorporation of fatty acids into complex lipids is time-dependent. Our data further show that the defect in lecithin and triglyceride synthesis observed for saturated fatty acids does not reflect impaired "loading" of the plasma membrane during the process of aggregation, but rather defective incorporation of free fatty acids from the membrane. Since the membrane-associated fatty acids were retained by the platelet despite vigorous washing, the defect presumably lies beyond the transfer of fatty acids from the exterior of the platelet to the more internal site of lipid assembly.

The observations derived from the acetate, glycerol, and fatty acid incorporation studies are consistent with the general hypothesis that aggregation of platelets by both thrombin and polylysine is associated with a defect in complex lipid assembly from fatty acids either synthesized within the cell or taken up from the plasma. Since we have previously shown that the bulk of fatty acids formed from acetate are saturated, the defect in incorporation of newly synthesized fatty acids into lipid complements our observations with palmitic and stearic acids.

The mechanism by which thrombin causes depression of incorporation of all fatty acids into triglycerides and of saturated fatty acids into phosphoglycerides while causing stimulation of incorporation of oleic acid remains unknown. However the combined data suggest that thrombin inhibits de novo assembly of complex lipids at a step common to both phospholipids and glycerides. In addition it may, by altering the configuration of the platelet membrane or by releasing endogenous phospholipase, enhance acylation of monacyl phospholipid receptors. Direct evidence for a thrombin-induced alteration of the conformation of the platelet surface has recently been presented (15). The overall rate of incorporation of unsaturated fatty acids into total platelet lecithin might then reflect a combination of two opposing processes-impaired novo lecithin formation and accelerated direct acylation. Elsbach, Pettis and Marcus (16) were unable to demonstrate an effect of thrombin on the direct acylation of platelet lecithin. However, they used a high concentration of thrombin $(5 \mathrm{U} / \mathrm{ml})$ in a buffer medium-conditions which we found (Fig. 1) to impair complex lipid formation.

In their experiments, Lewis and Majerus (3) noted that trypsin affected glycerol incorporation by platelets as well as thrombin, although the effect was fivefold less than that of thrombin. Further, they observed that the effect of trypsin could be abolished by preincubation of the enzyme with soybean trypsin inhibitor, and they suggested that the effects of both agents were mediated by proteolysis presumably of a "thrombin-sensitive protein of platelet membrane (17)." More recently Majerus and his associates have indicated that the thrombin-sensitive protein might not be the direct substrate for thrombin (18). They have also shown that plant phytohemagglutinins aggregate platelets and mimic the action of thrombin including the release of the thrombin-sensitive protein from the platelet membrane (15). Therefore they have questioned their previous assumption that thrombin acts entirely by a direct proteolytic process.

Our data also suggest that the effect of thrombin on platelet lipid metabolism is not solely a consequence of its proteolytic action. The mechanism by which the cationic polypeptide, poly-l-lysine, interacts with platelets to cause aggregation is unknown. Polylysine has no intrinsic proteolytic effect. Presumably, polylysine is first bound to platelets by its epsilon amino groups. Polylysine does not induce the release of serotonin, ATP, or ADP from rabbit platelet granules (19). Thrombin has a complex effect on platelet aggregation (20). In plateletrich plasma, it initiates primary platelet aggregation, presumably by a direct proteolytic action, causing release of platelet nucleotides which then initiate a second wave of platelet aggregation. Thrombin also causes irreversible fusion of platelet aggregates. In our studies we utilized conditions-low $\mathrm{pH}$, absence of fibrinogenwhich limit the effect of thrombin to primary aggregation in that the platelets could not respond with secondary aggregation to the released intracellular constituents. We suggest that the effects of polylysine and thrombin on lipid metabolism are linked through their ability to initiate primary aggregation, a property shared by trypsin, and that the effects of both agents on lipicl metabolism are secondary to a process initiated within the platelet by aggregation. At least one of the consequences of aggregation may be proteolysis of key membrane proteins by degradative enzymes located within the platelet. In preliminary experiments with Dr. Robert Rosenberg, we have demonstrated that both thrombin and polylysine cause similar alterations in the sodium dodecyl sulfate polyacrylamide gel electrophoretic patterns of platelet membrane preparations consistent with the effects now reported for plant phytohemagglutinins (16).

\section{ACKNOWLEDGMENTS}

It is a pleasure to recognize the skilled technical assistance of Ms. Susan Greene, Perla Schmidt, and Mr. George Bury.

This work was supported by grants HL-11414 and HI.10641 from The National Heart Institute.

\section{REFERENCES}

1. Deykin, D., and R. K. Desser. 1968. The incorporation of acetate and palmitate into lipids by human platelets. J. Clin. Invest. $47: 1590$.

2. Deykin, D., F. Cochios, G. de Camp, and A. Lopez. 1968. Hepatic removal of activated factor $\mathrm{X}$ by the perfused rabbit liver. Am. J. Physiol. 214: 414. 
3. Lewis, N., and P. W. Majerus. 1969. Lipid metabolism in human platelets. II. De novo phospholipid synthesis and the effect of thrombin on the pattern of synthesis. J. Clin. Invest. 48: 2114.

4. Cohen, P., A. Derksen, and H. von den Bosch. 1970. Pathways of fatty acid metabolism in human platelets. J. Clin. Invest. $49: 128$.

5. Spector, A. A., J. C. Hoak, E. D. Warner, and G. L. Fry. 1970. Utilization of long-chain free fatty acids by human platelets. J. Clin. Invest. 49: 1489.

6. Okuma, M., M. Steiner, and M. Baldini. 1971. Lipid content and in vitro incorporation of free fatty acids into lipids of human platelets: the effect of storage at $4^{\circ} \mathrm{C}$. Blood J. Hematol. 38 : 27.

7. Hoak, J. C., A. A. Spector, G. L. Fry, and B. C. Barnes. 1972. Localization of free fatty acids taken up by human platelets. Blood J. Hematol. 40: 16.

8. Hennes, A. R., K. Awai, K. Hammarstrand, and G. Duboff. 1966. Carbon-14 in carboxyl carbon of fatty acids formed by platelets from normal and diabetic subjects. Nature (Lond.). 210: 839.

9. Majerus, P. W., M. B. Smith, and G. H. Clamon. 1969. Lipid metabolism in human platelets. I. Evidence for a complete fatty acid synthesizing system. J. Clin. Invest. 48: 156 .

10. Okuma, M., M. Steiner, and M. G. Baldini. 1971. Incorporation of acetate and fatty acids into lipids of rat platelets. Proc. Soc. Exp. Biol. Med. 136: 842.

11. Corn, M. 1966. Effect of thrombin on glycolysis of fresh and stored platelets. J. Appl. Physiol. 21: 62.
12. Karpatkin, S. 1967. Studies on human platelet glycolysis. Effect of glucose, cyanide, insulin, citrate and agglutination and contraction on platelet glycolysis. J. Clin. Invest. 46: 409.

13. Warshaw, A. L., Laster, L., and N. R. Shulman. 1966. The stimulation by thrombin of glucose oxidation in human platelets. J. Clin. Invest. 45: 1923.

14. Steiner, M., and A. Kuramoto, A. 1971. Ser. Haematol. 6: 98 .

15. Majerus, P., and G. N. Brodie. 1972. The binding of phytohemagglutinins to human platelet plasma membranes. J. Biol. Chem. 247: 4253.

16. Elsbach, P., P. Pettis, and A. Marcus. 1971. Lysolecithin metabolism by human platelets. Blood J. Hematol. 37 : 675.

17. Baenziger, N. L., G. N. Brodie, and P. W. Majerus. 1971. A thrombin-sensitive protein of human platelet membranes. Proc. Natl. Acad. Sci. U. S. A. 68: 240.

18. Baenziger, N. L., G. N. Brodie, and P. W. Majerus. 1972. Isolation and properties of a thrombin-sensitive protein of human platelets. J. Biol. Chem. 247: 2723.

19. Jenkins, C. S. P., M. A. Packham, R. L. KinloughRathbone, and J. F. Mustard. 1971. Interactions of polylysine with platelets. Blood J. Hematol. 37: 395.

20. White, J. G. 1972. Platelet morphology and function. In Hematology. W. J. Williams, E. Beutler, A. J. Erslev, and R. W. Rundles, editors. McGraw-Hill Book Co., New York. 1023. 